\title{
Genotype by Environment Interaction for Somatic Cell Score Across Bulk Milk Somatic Cell Count and Days in Milk
}

\author{
M. P. L. Calus, ${ }^{\star 1}$ L. L. G. Janss, ${ }^{*}+$ and R. F. Veerkamp \\ *Animal Sciences Group, P.O. Box 65, 8200 AB Lelystad, The Netherlands \\ †Statistical Animal Genetics Group, Institute of Animal Science Swiss Federal Institute of Technology, ETH Zentrum, \\ $\mathrm{CH} 8092$ Zurich, Switzerland
}

\section{ABSTRACT}

The objective of this paper was to investigate the importance of a genotype $\times$ environment interaction $(G$ $\times$ E) for somatic cell score (SCS) across levels of bulk milk somatic cell count (BMSCC), number of days in milk (DIM), and their interaction. Variance components were estimated with a model including random regressions for each sire on herd test-day BMSCC, DIM, and the interaction of BMSCC and DIM. The analyzed data set contained 344,029 test-day records of 24,125 cows, sired by 182 bulls, in 461 herds comprising 13,563 herd test-days. In early lactation, considerable $\mathrm{G} \times \mathrm{E}$ effects were detected for SCS, indicated by 3 -fold higher genetic variance for SCS at high BMSCC compared with SCS at low BMSCC, and a genetic correlation of 0.72 between SCS at low and at high BMSCC. Estimated G $\times \mathrm{E}$ effects were smaller during late lactation. Genetic correlations between SCS at the same level of BMSCC, across DIM, were between 0.43 and 0.89 . The lowest genetic correlation between SCS measures on any 2 possible combinations of BMSCC and DIM was 0.42. Correlated responses in SCS across BMSCC and DIM were, on some occasions, less than half the direct response to selection in the response environment. Responses to selection were reasonably high among environments in the second half of the lactation, whereas responses to selection between environments early and late in lactation tended to be low. Selection for reduced SCS yielded the highest direct response early in lactation at high BMSCC.

Key words: somatic cell count, genotype $\times$ environment interaction, reaction norm model, test-day model

\section{INTRODUCTION}

Individual measures of SCC of dairy cows are used as an indicator trait for mastitis. Management and breeding decisions aim to reduce the SCC as a way to

Received November 15, 2005.

Accepted August 3, 2006.

${ }^{1}$ Corresponding author: mario.calus@wur.nl decrease the incidence of mastitis (Emanuelson, 1988; Weller et al., 1992; Philipsson et al., 1995). Another reason to reduce the SCC is to decrease the bulk milk SCC (BMSCC), which above a certain value results in a discount in milk price for the farmer (Veerkamp et al., 1998; Productschap Zuivel, 2004). A wide range of BMSCC are present across herds, which can be at least partly explained by differences in management between herds (Barkema et al., 1998a; Barkema et al., 1999) and is also related to the presence of mastitis pathogens, because an important part of the genetic variance in SCC is caused by mastitis. Therefore, the question arises whether these management differences reflected in BMSCC affect genetic parameters for SCC and responses to selection for reduced SCC.

Selection responses could be affected if a genotype $\times$ environment interaction $(\mathbf{G} \times \mathbf{E})$, also known as genetic variance of environmental sensitivity, exists for SCC. The importance of reported $\mathrm{G} \times \mathrm{E}$ for the SCS is limited. Sire $\times$ herd interaction effects for SCS have been shown to explain between 0 and 3\% of the total phenotypic variance (Banos and Shook, 1990; Schutz et al., 1994; Samore et al., 2001). Estimated genetic correlations between SCS expressed in herd environments with low vs. high average SCC were mainly close to unity (Castillo-Juarez et al., 2000; Raffrenato et al., 2003; Calus et al., 2005b), apart from a reported value of 0.80 estimated for Swedish Holsteins (Carlén et al., 2005), and reached a value as low as 0.83 when environments were defined based on management practices that enhanced milk production (Raffrenato et al., 2003). All these studies were based on lactation average SCS, and no results are available on the $\mathrm{G} \times \mathrm{E}$ of SCS based on test-day records. The $\mathrm{G} \times \mathrm{E}$ in SCS on the test-day level might be stronger because of short-term changes in the environment, such as an increased incidence of mastitis infection.

In this paper, we investigated the magnitude of genotypic, environmental, and $\mathrm{G} \times \mathrm{E}$ effects on SCS related to herd environment, as defined by herd test-day BMSCC, DIM, and the interaction of BMSCC and DIM for the individual cow. 


\section{MATERIALS AND METHODS}

\section{Data}

In total, 6,770,924 test-day records were available from Dutch dairy herds during 1997, 1998, and 1999, including repeated lactations. All animals were at least 75\% Holstein-Friesian. To meet computing limitations, the number of records was reduced to $1,663,898$ by randomly selecting $25 \%$ of all herds. Herds needed at least 20 records on each herd test-day. Records before 5 DIM and after 365 DIM were deleted, as were records of animals with fewer than 5 test-day records. This last criterion was applied to avoid bias attributable to inclusion of incomplete lactation records in the analysis (Pool and Meuwissen, 2000). The average SCC of records deleted in this step was 207,000 cells $/ \mathrm{mL}$, whereas the average SCC of the remaining records was 186,000 cells $/ \mathrm{mL}$. This indicates that the deleted records had a higher than average proportion of affected records. Further, the records of animals calving for the first time at an age of less than $640 \mathrm{~d}$ were deleted, as well as records of parity 5 and higher. These editing steps reduced the number of test-day records to $1,087,635$ (28,322 herd test-days). Additional editing steps deleted sires with fewer than 25 daughters, sires with daughters in fewer than 3 herd test-days, and herd test-days with daughters of fewer than 3 sires. Finally, herd testdays with fewer than 5 remaining records were deleted. The final data set contained 696,826 test-day records of 49,130 animals in 947 herds on 27,532 herd test-days. For each herd test-day, the BMSCC was calculated as the average of all available SCC records on that herd test-day, weighted by individual milk production:

\section{$\mathrm{BMSCC}=$ \\ $\underline{\sum_{1}^{i}[(\text { individual test day SCC }) \times(\text { individual test day milk yield })]}$ \\ total milk herd test day milk yield}

for $i$ animals in a certain herd test-day. The SCS was calculated from the SCC [SCS $\left.=\log _{2}(\mathrm{SCC} / 100,000)+3\right]$.

For estimation of variance components and breeding values using a sire model, the final data set was halved by randomly selecting half of the herds to enable use of daughter performance in the other $50 \%$ of the final data set to check the predictive ability of sire PTA. This last step selected 344,029 test-day records of 24,125 cows in 461 herds on 13,563 herd test-days (the other half contained 352,797 test-day records). The pedigree included 479 animals, of which 182 were sires of animals with records, 159 were paternal granddams of animals with records, and the other 138 were male ancestors of sires or paternal granddams.

\section{Random Regression Model}

Variance components were estimated using a sire model, assuming that SCS was the same trait in different lactations apart from the fixed effect corrections. Random effects were included for sire and cow. The genetic sire effect was modeled by applying random regressions (RR) 1) on DIM, to account for differences in individual daughter lactation curves; 2 ) on herd testday BMSCC, to account for differences in environmental sensitivity to changing BMSCC; and 3) on the interaction between BMSCC and DIM, to account for specific differences in lactations curves in environments with different BMSCC. Models were fitted with and without $\mathrm{RR}$ on the interaction between BMSCC and DIM. The within-lactation animal effect was modeled by applying RR (for each lactation separately) on DIM, to account for individual differences in lactation curves, and on herd test-day BMSCC, to account for changes in variances with changing BMSCC. The between-lactation animal effect was modeled by random effects for each animal. The RR were applied to Legendre polynomial coefficients (Kirkpatrick et al., 1990) representing BMSCC, DIM, and the interaction between them. Heterogeneous residual variances were included in the model for 25 groups that were formed by first splitting the data into 5 groups with equal numbers of records based on increasing BMSCC, and then splitting the data into 5 groups with equal numbers of records based on increasing DIM. Residual covariances were assumed to be zero. The residual groups contained between 8,166 and 17,219 test-day records. To account for within-residual-group averages, a fixed effect was added for each residual group as well. Other fixed effects were included in the model for mean, year-season of calving, parity, and herd test-day. Fixed regressions were included to account for age at calving within parity, breed of cow, DIM within parity, and the interaction between DIM and BMSCC. No fixed regression on BMSCC was included because all animals within the same herd testday were associated with the same BMSCC, and effects of BMSCC were therefore accounted for by the fixed effect for herd test-day.

The model was

$$
\begin{gathered}
Y_{i k l n p q}=\mu+\text { FIXED EFFECTS } \\
+\sum_{j=0}^{10} \beta_{i j} P_{i j l}+\sum_{j=0}^{10} \gamma_{j} Q_{i j k l q} \\
+\left[\sum_{m=0}^{s} \alpha_{m n} R_{i m q}+\sum_{o=1}^{t} \phi_{o n} S_{i o q}+\sum_{r=1}^{u} \lambda_{r n} T_{i o q}\right] \\
+\left[\sum_{m=0}^{s} \varpi_{i m q} R_{i m q}+\sum_{o=1}^{t} \rho_{i o q} S_{i o q}\right]+\operatorname{animal}_{q}+E_{i k l n p q}
\end{gathered}
$$

Journal of Dairy Science Vol. 89 No. 12, 2006 
where $Y_{i k l n p q}$ is an SCS record of cow $q$; $\mu$ is the average performance over all animals; FIXED EFFECTS include year-season of calving, herd test-day, residual group, and second-order polynomial regressions on age at calving and percentage of Holstein-Friesian, Dutch Friesian, and Meuse-Rhine-Yssel genes,

$$
\sum_{j=0}^{10} \beta_{i j} P_{i j l}
$$

is a fixed 10th-order regression within parity $i(1,2, \ldots$, 4) $\left(\beta_{i j}\right)$ on a polynomial coefficient reflecting $\operatorname{DIM} l\left(P_{i j l}\right)$, resembling the average lactation curve in the population;

$$
\sum_{j=0}^{10} \gamma_{j} \boldsymbol{Q}_{i j k l q}
$$

is a fixed 10th-order regression $\left(\gamma_{j}\right)$ on a polynomial coefficient resembling the interaction of BMSCC at herd test-day $k$ and DIM $l$ of cow $q\left(Q_{i j k l q}\right) ; \alpha_{m n}$ is coefficient $m$ of the RR on the orthogonal polynomial coefficients of herd test-day BMSCC of the daughters of sire $n ; \phi_{o n}$ is coefficient $o$ of the RR on the orthogonal polynomial coefficients of DIM of the daughters of sire $n ; \lambda_{r n}$ is coefficient $r$ of the RR on the orthogonal polynomial coefficients of the interaction of herd test-day BMSCC and DIM of the daughters of sire $n$; $\omega_{i m q}$ is coefficient $m$ of the RR on the orthogonal polynomial coefficients of herd test-day BMSCC of cow $q$ in parity $i$ (permanent environment within lactation); $\rho_{i o q}$ is coefficient $o$ of the RR on the coefficients of the orthogonal polynomials of DIM of cow $q$ in parity $i$ (permanent environment within lactation); $s, t$, and $u$ are the largest significant estimable coefficients $m, o$, and $r$ of the RR on BMSCC, DIM, and their interaction, respectively; $R_{i m q}, S_{i o q}$, and $T_{i o q}$ are polynomial coefficients reflecting DIM, BMSCC, and the interaction between them of cow $q$ in parity $i$; animal $_{q}$ is a random effect correcting for the betweenlactation permanent environmental variance of cow $q$; and $E_{\text {iklnpq }}$ is the residual effect of cow $q$ in herd testday $k$ within residual group $p(P=1,2, \ldots, 25)$.

Variances and covariances were modeled across BMSCC and DIM for additive genetic effects and permanent environmental effects. Residual variances were estimated for each residual group, and residual covariances between groups were assumed to be zero. Heritabilities were calculated as 4 times the sire variance divided by the sum of the residual variance, the withinand between-lactation permanent environmental variance, and the sire variance. All analyses were performed with AS-REML (Gilmour et al., 2002).

\section{Stepwise Increase of Orders of RR}

The RR order modeling sire and cow effects was increased in a stepwise manner. At first, first-order RR on BMSCC for sire and cow were included in the model. The order of the RR on DIM were increased for sire and cow effects together, until the highest order either did not significantly improve the fit of the model or was not estimable. A similar approach was used for BMSCC. The model was applied both with and without an RR for sire effects on the interaction between BMSCC and DIM. The order of the RR on the interaction was allowed to be at a maximum as large as the smallest order of the RR on either DIM or BMSCC. Likelihood ratio tests were used to identify the highest significant estimated orders for the sire and cow effects $(P<0.05)$. The test statistic was twice the difference in log likelihood between models with order $n$ and $n-1$, respectively. The order of the fixed regressions on DIM and the interaction between DIM and BMSCC was arbitrarily kept constant at 10, to allow comparison of log likelihoods of models with different orders for the RR.

\section{Correlated Responses Across Environments}

Correlated responses across environments were investigated for a situation reflecting selection solely on sire PTA for SCS in one environment and the response in another environment. The assumption was that for each combination of BMSCC and DIM, the selection differential was one genetic standard deviation. Based on the estimated genetic variances and correlations, correlated responses were calculated across BMSCC and DIM as

$$
C R_{D x 1, B y 1}=\operatorname{ir}_{(D x 1, B y 1),(D x 2, B y 2)} \sigma_{D x 1, B y 1}
$$

where $C R_{D x 1, B y 1}$ is the correlated response in SCS at DIM $x_{1}$ and BMSCC $y_{1}, i$ is the selection intensity (set to one genetic standard deviation for each situation), $r_{(D x 1, B y 1),(D x 2, B y 2)}$ is the additive genetic correlation between SCS at DIM $x_{1}$ and BMSCC $y_{1}$, and SCS at DIM $x_{2}$ and BMSCC $y_{2}$, and $\sigma_{D x 1, B y 1}$ is the additive genetic standard deviation of SCS at DIM $x_{1}$ and BMSCC $y_{1}$ (Falconer and Mackay, 1996).

\section{Predicted Performance Based on BMSCC and Sire PTA}

To enable comparison of effects of management changes (BMSCC) and selection (sire PTA) on SCS, the combined effects of BMSCC and PTA of sires on phenotypic SCS were estimated. This was done by fitting the RR model (RRM; i.e., with the highest estimable orders for the RR) with a 10th-order fixed polyno- 
Table 1. Log likelihood and log likelihood rate test statistic (LRT) comparing different models with and without a first-order random regression (RR) on the interaction between bulk milk SCC (BMSCC) and DIM

\begin{tabular}{|c|c|c|c|}
\hline \multicolumn{2}{|c|}{ Order RR } & \multirow[b]{2}{*}{ Log likelihood $^{2}$} & \multirow[b]{2}{*}{$\mathrm{LRT}^{3}$} \\
\hline $\mathrm{BMSCC}^{1}$ & $\mathrm{DIM}^{1}$ & & \\
\hline 1 & 1 & -1737120.38 & 46.66 \\
\hline 1 & 2 & -1732476.70 & 58.20 \\
\hline 1 & 3 & -1730467.97 & 53.73 \\
\hline 1 & 4 & -1729522.51 & 56.37 \\
\hline
\end{tabular}

${ }^{1}$ Orders of the RR for sire and cow effects on the BMSCC and DIM.

${ }^{2} \mathrm{Log}$ likelihood of the model including the first-order $\mathrm{RR}$ on the interaction between DIM and BMSCC.

${ }^{3}$ The LRT was calculated as twice the difference in log likelihood of models with and without the linear regression on the interaction between BMSCC and DIM. Differences between the models were significant if the LRT statistic was $>3.84$.

mial regression on BMSCC, instead of a fixed herd testday effect. The fixed polynomial regression was chosen here because it estimates average SCS for herds with a given BMSCC, which is suitable for predicting the average performance across herds. Average EBV were zero within environments; hence, the average phenotypic performance estimated with the 10th-order regression on BMSCC was combined with a PTA of zero. Within a herd environment, the change in phenotypic performance was calculated as a correlated response to selection in an environment with an average BMSCC of 184,000 cells $/ \mathrm{mL}$, thus reflecting the effects of selecting sires on a national index for SCS in herds with different BMSCC levels. The range of sires' PTA considered was 2 sire standard deviations in the average environment (estimated at 0.24 ), to include approximately $95 \%$ of the range of sires' PTA. The PTA considered were estimated at an average stage of lactation of 167 DIM.

\section{RESULTS}

The SCS values of included test-day records ranged from -3.64 to 9.64 , having a mean value of 2.50 and standard deviation of 1.70 . The DIM ranges for the different groups, used to estimate heterogeneous residual variances, were 6 to 76,77 to 141,142 to 207, 208 to 279 , and 280 to 365 . The BMSCC $\left(\times 10^{3}\right.$ cells $\left./ \mathrm{mL}\right)$ ranges for those groups were 25 to 111,112 to 141,142 to 197,198 to 274 , and 275 to 1,024 .

The RRM that best fit the data based on the log likelihood ratio test included a fourth-order RR on DIM, and first-order RR on BMSCC and on the interaction between BMSCC and DIM (Table 1). Models with higher order RR on DIM and BMSCC did not converge. Differences in log likelihood were larger for pairs of models with increasing order on DIM than for models with and without an $\mathrm{RR}$ on the interaction between DIM and BMSCC.

The pattern of sire variance changed between models with and without an RR on the interaction between BMSCC and DIM (Figure 1). The largest differences were found in estimates early in lactation on herd testdays with a high BMSCC. The estimated sire variances for the RR model with an interaction between BMSCC and DIM were nearly twice as high as the estimates of the model without that effect. In the remainder of this paper, all reported results are from the RRM including a fourth-order RR on DIM, and first-order RR on BMSCC and on the interaction between BMSCC and DIM unless stated otherwise.

\section{Genetic Parameters for SCS Across BMSCC and DIM}

Estimated heritabilities for SCS in early lactation had the highest values at high BMSCC, whereas late in lactation the highest values were found at low BMSCC (Table 2), following the sire variance profile. Heritabilities for SCS were lowest early in lactation at low BMSCC (Table 2). Estimated genetic correlations between SCS measures at extreme DIM in the same environments ranged from 0.43 to 0.57 (Table 3). Trends in estimated genetic correlations were comparable between pairs of DIM across BMSCC, but correlations dropped in most cases in which the difference in BMSCC increased (Table 3). Surprisingly, genetic correlation estimates between DIM pairs within the same BMSCC environment were, in most cases, lower than the estimates of the same pair in different environments. Genetic correlations between SCS in environments with extreme BMSCC were as low as 0.72 early in lactation, but were close to unity late in lactation. The lowest estimated genetic correlation was 0.42 , between a situation early in lactation at high BMSCC and a situation late in lactation at low BMSCC.

\section{Sires' PTA for SCS Across DIM and BMSCC}

To gain insight into the differences in patterns of PTA of sires across BMSCC, the PTA for SCS of the 10 sires with the most daughter records in the data were plotted across BMSCC at 40 and 315 DIM (Figure 2). At both 40 and 315 DIM, the response of the sires' PTA to increasing BMSCC was that some of the sires' PTA decreased, whereas some of the sires' PTA increased. When comparing sire A and sire B, sire B had a more desirable PTA across BMSCC (i.e., a lower value) early in lactation, whereas sire A had a more desirable PTA across BMSCC late in lactation. The breeding value of sire A decreased with increasing BMSCC early in 

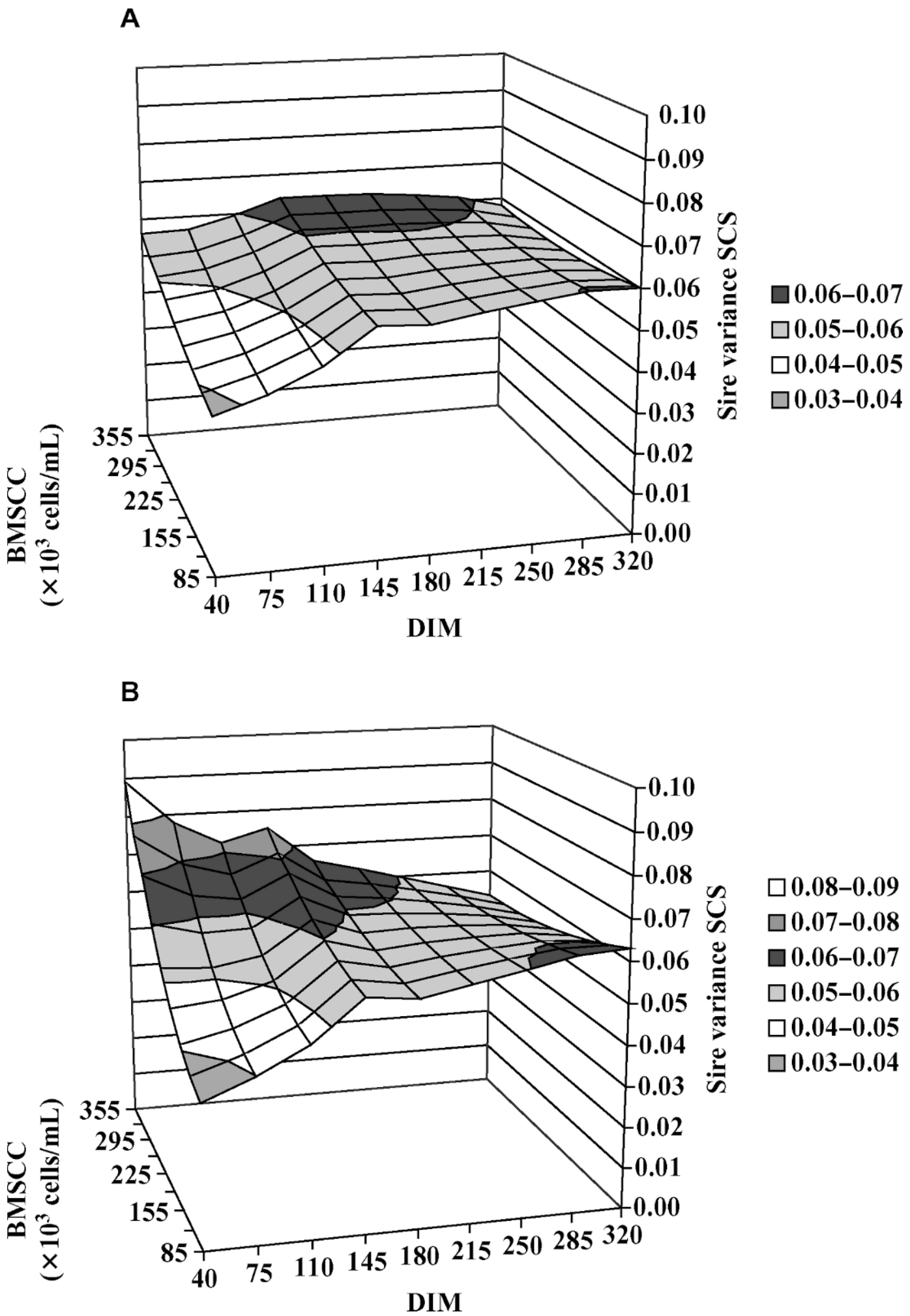

Figure 1. Sire variances of SCS on herd test-days with different bulk milk SCC (BMSCC) and at different DIM, estimated with a random regression model (RRM) with a fourth-order random regression on DIM and a first-order random regression on BMSCC (A) or with a fourthorder random regression on DIM and a first-order random regression on BMSCC, and the interaction between BMSCC and DIM (B). 
Table 2. Estimated heritabilities ${ }^{1}$ of SCS on herd test-days with different bulk milk SCC $\left(\times 10^{3}\right.$ cells/mL; BMSCC $)$ and at different DIM, estimated with a random regression $(R R)$ model with a fourthorder RR on DIM and first order RR on BMSCC, and the interaction between BMSCC and DIM ${ }^{2}$

\begin{tabular}{llllll}
\hline & \multicolumn{5}{c}{ DIM } \\
\cline { 2 - 6 } BMSCC & 40 & 110 & 175 & 245 & 315 \\
\hline 85 & 0.06 & 0.08 & 0.11 & 0.14 & 0.16 \\
130 & 0.06 & 0.08 & 0.11 & 0.13 & 0.15 \\
175 & 0.06 & 0.08 & 0.10 & 0.13 & 0.14 \\
230 & 0.07 & 0.08 & 0.10 & 0.11 & 0.13 \\
360 & 0.10 & 0.09 & 0.10 & 0.10 & 0.11 \\
\hline
\end{tabular}

${ }^{1}$ Approximate standard errors of the heritabilities ranged from 0.01 to 0.03 .

${ }^{2}$ Chosen values for BMSCC and DIM represent the 10th, 30th, 50 th, 70th, and 90 th percentiles of the data.

lactation, whereas it increased with increasing BMSCC late in lactation.

\section{Selection Response for SCS Across DIM and BMSCC}

Correlated selection responses in all environments were calculated based on selection in all environments (Table 4). Within a given environment, the smallest correlated responses were less than half as large as the direct responses to selection. Selection responses in a given environment were always highest based on selection in the same environment. However, indirect selection in some environments yielded a higher response than did direct selection. For selection early in lactation (40 DIM), correlated responses were lowest late in lacta- tion (315 DIM). For selection later in lactation (175 and 315 DIM), the lowest correlated responses were estimated in an environment with BMSCC of 85,000 cells $/ \mathrm{mL}$ and 40 DIM. Correlated responses across BMSCC tended to be lowest in herds with low BMSCC and highest in herds with high BMSCC. The correlated responses showed trends similar to those of the genetic correlations (Table 3). However, the differences in genetic variance across DIM and BMSCC also had an influence on the correlated responses, because selection in an environment with low BMSCC generally yielded a higher correlated response in environments with high BMSCC, rather than vice versa.

\section{DISCUSSION}

Breeding values were estimated depending on DIM and BMSCC. As a result, estimated breeding values represented a surface across DIM and BMSCC, rather than one single point, as is the case when DIM and BMSCC are ignored, or a line when only an RR on either DIM or BMSCC is performed. The RR on DIM was chosen to account for individual differences in SCS patterns across DIM. The RR on BMSCC was chosen, because BMSCC is related to the hygienic conditions on the farm (Barkema et al., 1999). Including 2 dimensions in the model (i.e., a fourth-order RR on DIM and a linear RR on BMSCC), implied that an animal pattern of the EBV for SCS across DIM was linearly scaled across BMSCC. A second model that also included an $\mathrm{RR}$ on the interaction between BMSCC and DIM did allow individual SCS patterns across DIM to be differ-

Table 3. Estimated genetic correlations ${ }^{1}$ between SCS on herd test-days with different bulk milk SCC $\left(\times 10^{3}\right.$ cells $/ \mathrm{mL}$; BMSCC) and at different DIM, estimated with a random regression model with a fourth-order random regression on DIM and a first-order random regression on BMSCC, and the interaction of BMSCC and $\mathrm{DIM}^{2}$

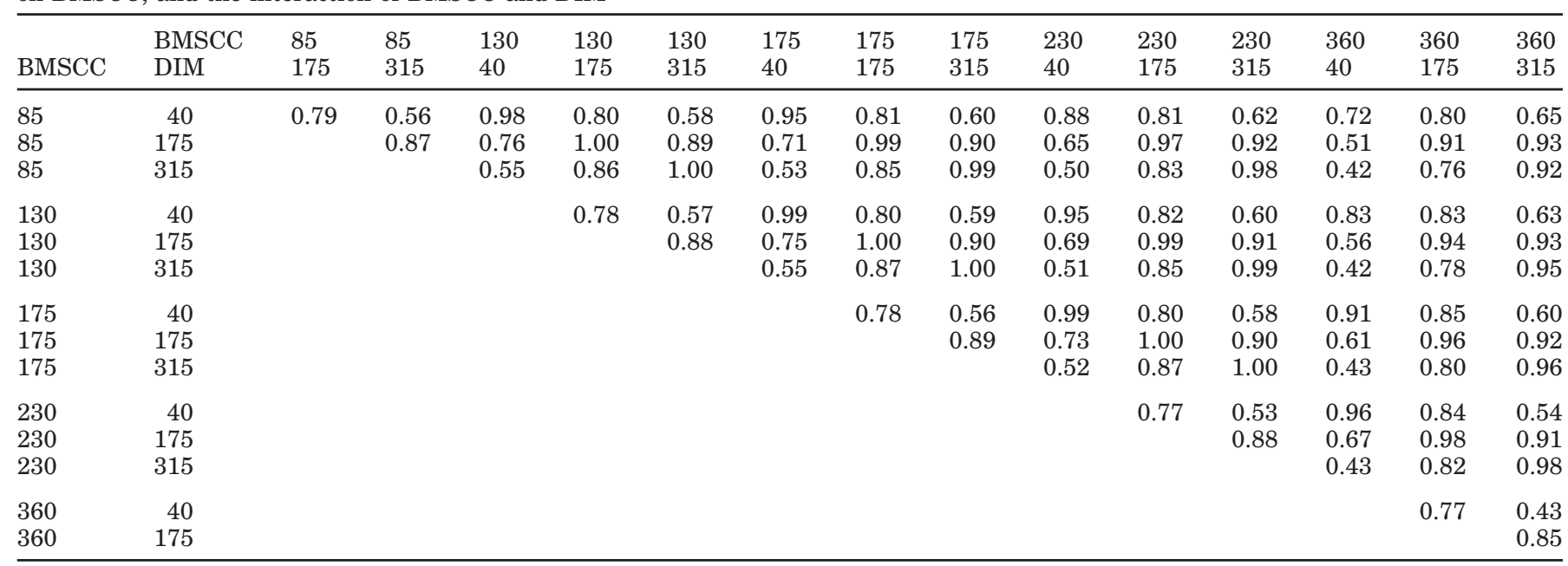

${ }^{1}$ Approximate standard errors ranged from 0.01 to 0.13 .

${ }^{2}$ Chosen values for BMSCC (DIM) represent the 10th, 30th, 50th, 70th, and 90th (10th, 50th, and 90th) percentiles of the data. 

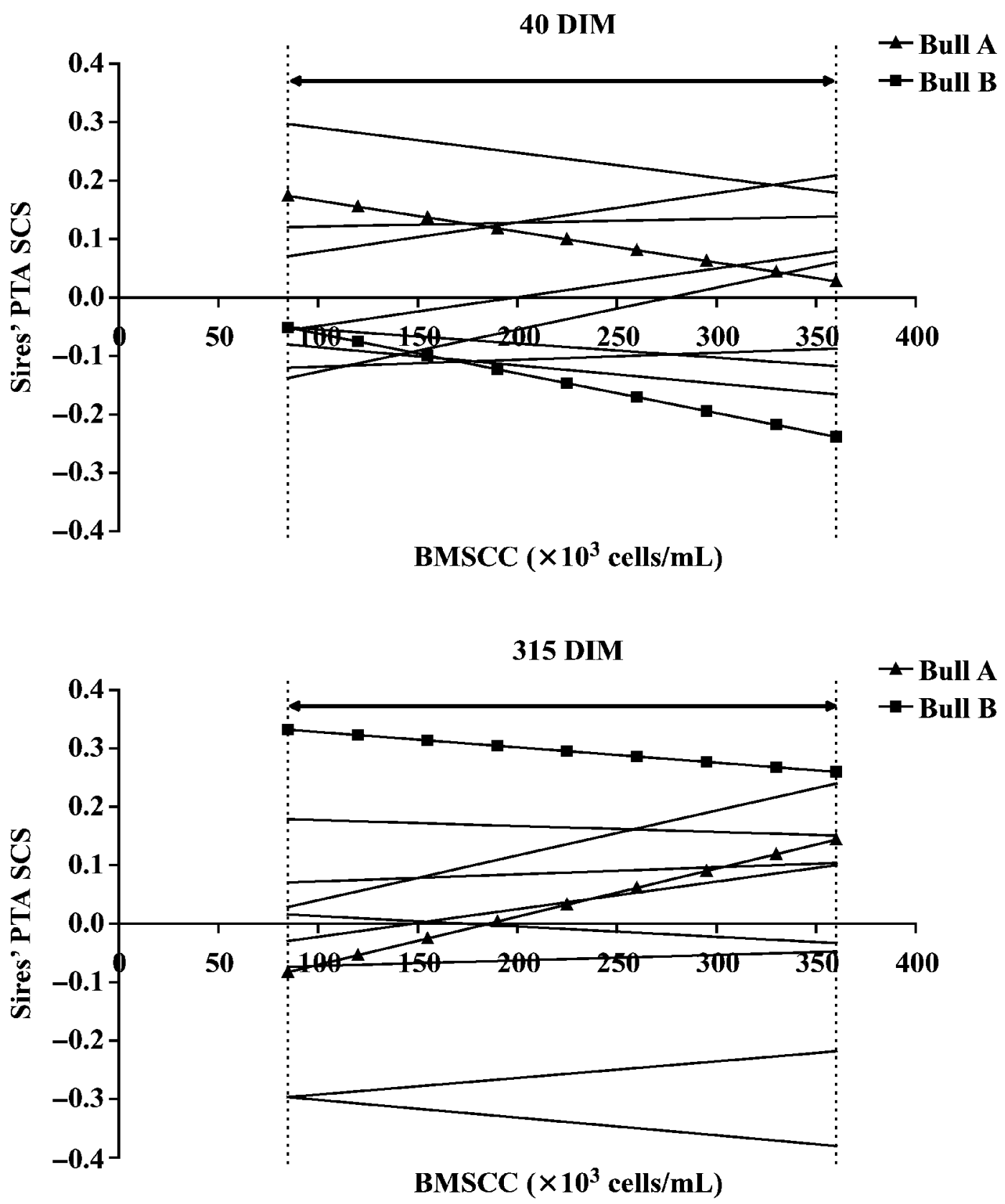

Figure 2. Predicted transmitting abilities estimated for sires with the most daughter records in the data across bulk milk SCC (BMSCC) at DIM of 40 and $315 \mathrm{~d}$.

ent across BMSCC. Some tendencies in estimated correlations were unexpected. For instance, when comparing genetic correlations between environments with DIM = 40 and $\mathrm{BMSCC}=85,000$ cells $/ \mathrm{mL}$ to environments with $\mathrm{DIM}=315$ with increasing BMSCC, estimated genetic correlations increased from 0.56 to 0.65 (Table 3 ). Those tendencies were unexpected, because genetic correlations between a trait in different environments are expected to be higher when environments are more simi- lar. However, the estimated genetic correlation between SCS at different levels of BMSCC, but at the same stage of lactation (i.e., DIM), did decrease when the values of BMSCC were further apart (Table 3). Possibly, data that combine different levels of BMSCC at the same stage of lactation are more informative for the model than are data that combine different levels of BMSCC at different stages of lactation. This could be a result of the parametrization of the RRM, because one set of 
Table 4. Calculated correlated responses of SCS at different values of bulk milk SCC $\left(\times 10^{3}\right.$ cells $/ \mathrm{mL}$; BMSCC $)$ and at different DIM $^{1}$

\begin{tabular}{|c|c|c|c|c|c|c|c|c|c|c|}
\hline \multicolumn{2}{|c|}{$\begin{array}{c}\text { Selection } \\
\text { environment }\end{array}$} & \multicolumn{9}{|c|}{ Response environment } \\
\hline & BMSCC & 85 & 85 & 85 & 175 & 175 & 175 & 360 & 360 & 360 \\
\hline BMSCC & DIM & 40 & 175 & 315 & 40 & 175 & 315 & 40 & 175 & 315 \\
\hline 85 & 40 & 0.187 & 0.184 & 0.140 & 0.197 & 0.191 & 0.144 & 0.219 & 0.205 & 0.151 \\
\hline 85 & 175 & 0.147 & 0.233 & 0.219 & 0.149 & 0.234 & 0.217 & 0.152 & 0.234 & 0.214 \\
\hline 85 & 315 & 0.104 & 0.203 & 0.251 & 0.111 & 0.201 & 0.239 & 0.126 & 0.196 & 0.214 \\
\hline 175 & 40 & 0.177 & 0.166 & 0.134 & 0.209 & 0.183 & 0.135 & 0.274 & 0.218 & 0.138 \\
\hline 175 & 175 & 0.151 & 0.231 & 0.214 & 0.162 & 0.236 & 0.213 & 0.185 & 0.248 & 0.213 \\
\hline 175 & 315 & 0.111 & 0.211 & 0.250 & 0.117 & 0.209 & 0.241 & 0.129 & 0.207 & 0.223 \\
\hline 360 & 40 & 0.135 & 0.118 & 0.105 & 0.190 & 0.145 & 0.103 & 0.302 & 0.200 & 0.099 \\
\hline 360 & 175 & 0.149 & 0.212 & 0.191 & 0.176 & 0.227 & 0.193 & 0.233 & 0.258 & 0.197 \\
\hline 360 & 315 & 0.122 & 0.216 & 0.233 & 0.124 & 0.217 & 0.232 & 0.129 & 0.219 & 0.232 \\
\hline
\end{tabular}

${ }^{1}$ The environment of the correlated response is characterized by column values for BMSCC and DIM, and the selection environment is characterized by row values for BMSCC and DIM. Chosen values for BMSCC and DIM represent the 10th, 50th, and 90th percentiles of the data. Responses to selection in the selection environment are given on the diagonal.

parameters models the genetic (co)variances across 2 directions (DIM and BMSCC) and combinations thereof. The unexpected tendencies were comparable for a model without RR on the interaction between DIM and BMSCC, as well as for a model with RR of order 3 on DIM and an RR of order 2 on BMSCC (results not shown). The possible inflexibility of RRM could be overcome by using models that have more flexible (co)variance structures described by fewer parameters, such as structured antedependence models (Nunez-Anton and Zimmerman, 2000; Jaffrezic et al., 2004). Higher order RR on BMSCC and the interaction between DIM and BMSCC could not be fitted together with an RR of order 4 on DIM, but would be useful to further identify the background of the differences in expressed genetic variance. Fitting higher orders could perhaps be feasible by reducing the ranks of the (co)variance matrices in the RRM, or using alternative models such as structured antedependence models, as suggested above.

Animals were required to have at least 5 test-day records to be included in the analysis. This editing step deleted records with above-average SCS, likely leading to conservative estimates for $\mathrm{G} \times \mathrm{E}$ effects in early lactation. On the other hand, this editing step ensured that data were not extrapolated across DIM, which could have led to biased estimates across DIM (Pool and Meuwissen, 2000). In the models used to estimate variance components, fixed herd test-day effects were used to account for the herd environment. The advantage of fixed herd test-day effects compared with fixed regressions on a parameter reflecting the environment is that fixed herd test-day effects allow better correction for the specific circumstances in the same herd test- day (i.e., specific deviation of the mean), regardless of the value of the environmental parameter. This is important to avoid bias in the estimated environmentspecific genetic effects (i.e., $\mathrm{G} \times \mathrm{E}$ ). The results indicated that considerable $\mathrm{G} \times \mathrm{E}$ exists for SCS across DIM and herd environments. This $\mathrm{G} \times \mathrm{E}$ might come from different sources of variation (e.g., type of mastitis and incidence of mastitis) being involved in the genetic variation of SCC, and will have implications for the optimal selection strategies in breeding programs. Also, at the farm level this $\mathrm{G} \times \mathrm{E}$ has implications in that management and genetic selection need to be considered together and not as separate components for the reduction of SCC. Different sources of variation for SCC, the implications of $\mathrm{G} \times \mathrm{E}$ for breeding programs, and the optimal balance between management and genetic selection for the reduction of SCC are discussed below.

\section{Genetic Variation for $G \times E$ on SCS Across DIM and BMSCC}

The increase of the estimated heritability of SCS across DIM was in line with results of other studies applying test-day models to Holstein cow data (HaileMariam et al., 2001; Odegard et al., 2003; Koivula et al., 2004). Two of these studies found a similar increase in the genetic variance across DIM (Odegard et al., 2003; Koivula et al., 2004), although others found a stronger increase (Haile-Mariam et al., 2001). Estimated genetic correlations between extreme DIM ranged from 0.43 to 0.63 , which was in line with reported values ranging from 0.3 to 0.7 (Haile-Mariam et al., 2001; Odegard et al., 2003; Koivula et al., 2004). Responses to selection strongly depended on BMSCC 
and DIM, and in some situations selection in one environment yielded higher indirect than direct responses. In situations in which this occurred, the BMSCC was always higher in the response environment than in the selection environment, whereas DIM was mostly the same in both environments. This indicates that an increase in BMSCC in some situations might have a larger influence on expressed genetic variance than on the ranking of sires.

The resistance of cows against mastitis pathogens is reported to be lower early in lactation than in late lactation (Mallard et al., 1998), possibly because of increased milk production during these stages. The lower resistance early in lactation likely results in a higher incidence of mastitis, which might be one of the reasons why there was higher genetic variance for SCS early in lactation. In this study, a 3-fold higher genetic variance was found early in lactation in environments with high BMSCC than in environments with low BMSCC. The differences in genetic variance at low and high BMSCC may be largely due to a difference in the incidence of mastitis. A low BMSCC is associated with a higher risk of mastitis because of environmental pathogens such as Escherichia coli (Erskine et al., 1988; Miltenburg et al., 1996; Barkema et al., 1998b). Thus, the low estimated sire variance early in lactation at low BMSCC may be due to little or no challenge to the animals, but may also indicate that there was relatively little difference in susceptibility to environmental pathogens between the daughters of different sires. A high BMSCC is associated with a higher risk of mastitis attributable to contagious pathogens such as Streptococcus agalactiae and Staphylococcus aureus (Erskine et al., 1988; Wilson et al., 1997; Barkema et al., 1998b). Therefore, the high estimated sire variance early in lactation at high BMSCC might be caused by variability in infection rates among sires rather than variability in SCS for daughters with the same infection status, indicating that there are large genetic differences in susceptibility to contagious pathogens early in lactation between daughters of different sires. Contagious pathogens usually lead to elevated SCC for several test days, often leaving affected animals with an elevated SCC throughout the rest of the lactation (De Haas et al., 2002). In herds with high BMSCC and contagious pathogens, a relatively large proportion of the animals might have had an elevated SCC toward the end of the lactation. This might explain why differences between animals (i.e., genetic variance) were smaller toward the end of the lactation in high-BMSCC herds. Hence, in early lactation the difference in susceptibility may be the major cause of expressed variation among animals in these herds, and at the end of lactation the most important source of expressed genetic variation may be differences in SCS among affected animals. The relatively low estimated genetic correlation early in lactation between SCS at low and high BMSCC (i.e., 0.72) supports the hypothesis that the effect of different sources of variation is different in herds with low and high BMSCC.

Genetic correlations of SCS across environments, estimated on a lactation basis, are reported to be between 0.8 and unity (Castillo-Juarez et al., 2000; Raffrenato et al., 2003; Calus et al., 2005b; Carlén et al., 2005). Genetic correlations in this paper, estimated on a testday basis, indicated more reranking of sires across BMSCC early in lactation and comparable or less reranking of sires late in lactation (i.e., correlations ranged from 0.72 to 1.00). This further supports the idea that $\mathrm{G} \times \mathrm{E}$ for SCS is more important early in lactation, possibly because of the higher incidence of mastitis. It also shows that a more detailed analysis of phenotypic information (e.g., on a test-day basis rather than by lactation averages) reveals more $\mathrm{G} \times \mathrm{E}$. In this specific case, the use of herd test-day-specific BMSCC values would likely reflect temporal environmental changes, such as outbreaks of mastitis, whereas a herdyear average BMSCC probably would reflect average herd management.

\section{Implications for Breeding Programs}

Based on the estimated $\mathrm{G} \times \mathrm{E}$ for SCS between environments with different BMSCC and at different DIM, one can argue that the breeding goal to reduce SCS should depend on BMSCC and DIM. Another strategy might be to have one breeding goal for all environments and emphasize selection for reduced SCS in those circumstances in which reducing the SCS is the most important. Identification of those circumstances brings us back to the main reasons for reducing the SCS through selection: 1) to reduce the incidence of mastitis by using SCS as a predictor trait (Emanuelson, 1988; Weller et al., 1992; Philipsson et al., 1995), and 2) to decrease the chance of being penalized for a high BMSCC (Dekkers et al., 1996; Veerkamp et al., 1998). The incidence of mastitis is usually highest early in lactation (Erskine et al., 1988; Barkema et al., 1998b), and is also more strongly correlated with SCS in early lactation than in late lactation (De Haas et al., 2003). Thus, early in lactation, elevated SCS might be especially important as an indicator for incidence of mastitis. Reducing SCS as a way to decrease the BMSCC is likely more important at high BMSCC, because the chance of being penalized is higher. Therefore, the major focus in a breeding goal could be to decrease SCS early in lactation and at high BMSCC. Following this strategy, one should take into consideration that the selection using 
breeding values for a roughly average environment (BMSCC at 175,000 cells/mL and DIM at 175) gives a response in early lactation at high BMSCC as low as $60 \%$ of the possible selection response (Table 4). The results in Table 4 indicate that for selection for reduced SCS at high BMSCC early in lactation, the emphasis should be on environments early in lactation and on environments with average and above-average BMSCC. In these circumstances, heritabilities ranged from 0.06 to 0.10 (medium to high BMSCC). The approximate reliability of a sire EBV is $\mathrm{r}^{2}=\mathrm{n}_{\mathrm{e}} /\left(\mathrm{n}_{\mathrm{e}}+\lambda\right)$, where $\mathrm{n}_{\mathrm{e}}$ is the effective daughter size and $\lambda=\left(4-\mathrm{h}^{2}\right) / \mathrm{h}^{2}$. In a situation in which selection is on one trait while the response is on another trait, $\mathrm{h}^{2}$ is replaced by the factor $h_{X} h_{Y} r_{A}$, where $h_{X}$ and $h_{Y}$ are the square root of heritabilities of traits $\mathrm{X}$ and $\mathrm{Y}$, respectively, and $\mathrm{r}_{\mathrm{A}}$ is the genetic correlation between the 2 traits. This implies that to obtain a breeding value with a reliability of $80 \%$ for SCS early in lactation (40 DIM) at medium (175,000 cells $/ \mathrm{mL})$ or high BMSCC (360,000 cells $/ \mathrm{mL}), 251$ or 255 daughters, respectively, are required in an environment with BMSCC of 175,000 cells $/ \mathrm{mL}$ and at 175 DIM. From the same formulas, it follows that with direct selection early in lactation at medium or high BMSCC, respectively, 251 and 157 daughter records are needed to obtain sire EBV with a reliability of $80 \%$. This example illustrates that evaluating sires based on an average environment reduces accuracy in those circumstances in which decreasing the SCS might be the most important.

\section{Reducing SCS at the Farm Level}

Both management and genetic selection can be used to reduce SCS at the farm level, and the existence of $\mathrm{G} \times \mathrm{E}$ indicates that both should be considered simultaneously to evaluate their relative importance. To enable this, the average phenotypic performance for SCS was estimated as a function of BMSCC and sire PTA for SCS (Figure 3). The PTA for sires were based on the average environment, but the effects of selection were calculated specifically for each environment, thus depending on the genetic correlation and genetic SD in each BMSCC environment. Figure 3 allows a comparison of the average phenotypic SCS of daughters of a sire across environments, as well as a comparison of differences in the average phenotypic SCS of daughters of different sires in the same environment. Figure 3 shows that considerable benefits of using the best sire for SCS are obtained at both high and low levels of BMSCC. Sometimes it is argued that at high levels of BMSCC, farmers should first take management action before considering breeding for reduced SCS. Although this might be the quickest solution in the short term,

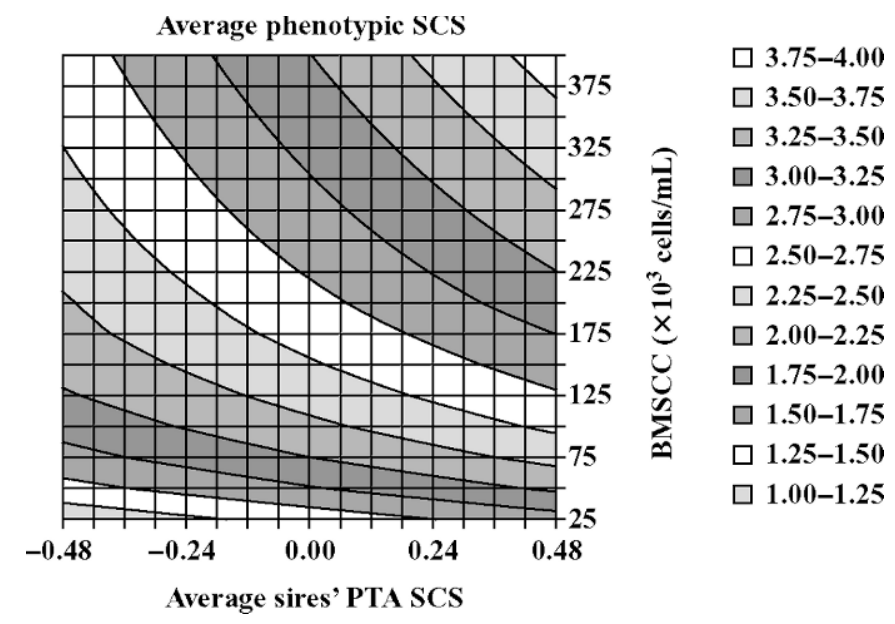

Figure 3. Contour plot reflecting the average phenotypic performance for SCS (by different colors) of animals that are in an environment with a bulk milk SCC (BMSCC), as indicated on the y-axis, and whose sires' PTA for SCS in the average environment are indicated on the $\mathrm{x}$-axis. The average environment is reflected by a BMSCC of 184,000 cells $/ \mathrm{mL}$ and an average stage of lactation of 167 DIM.

Figure 3 shows that at high BMSCC the benefits of selecting sires with the best PTA for SCS are considerable, and are greater than when selecting at average or low BMSCC.

Figure 3 also shows that for different values of BMSCC, a decrease in BMSCC does not lead to comparable changes in the average SCS. This is partly a consequence of the different scales of BMSCC and SCS (the latter being log-transformed), and the fact that BMSCC is an average of SCC weighted by daily milk production of the animals, whereas the average phenotypic SCS is not weighted. However, BMSCC (which is not log transformed) is preferred, because it is a widely known measure for the environment, whereas SCS (which is $\log$ transformed) is preferred because of its statistical properties. The difference in scales could be solved by calculating directly on the scale of SCC, ignoring the nonnormality of SCC. Comparison of PTA on the scales of SCC and SCS, both depending on BMSCC and DIM, indicated that PTA for SCC showed larger $\mathrm{G} \times \mathrm{E}$ effects, and actually better predicted average daughter performance than did PTA on the scale of SCS (Calus et al., 2005a). The log transformation might result in losing some important information, because the transformation primarily affects records with high SCS (i.e., records that are likely affected by mastitis). A better solution might be to consider a model that aims to identify animals (based on SCC) as either affected or healthy while not recording mastitis directly. Applying a reaction norm model could partly solve this problem, where the difference between affected and nonaffected records can be explained as a $\mathrm{G} \times \mathrm{E}$ effect, but other solutions, 
such as applying mixture models (Detilleux and Leroy, 2000), have been proposed.

\section{CONCLUSIONS}

Random regression models might lack sufficient flexibility to model $\mathrm{G} \times \mathrm{E}$ across more than one dimension, as indicated with some unexpected tendencies in estimated genetic correlations and indirect selection responses across environments. Estimated $\mathrm{G} \times \mathrm{E}$ effects on a test-day basis were greater than previously reported $\mathrm{G} \times \mathrm{E}$ effects based on lactation averages, indicating that a more detailed analysis of phenotypic information reveals more $\mathrm{G} \times \mathrm{E}$. Early in lactation, a strong $\mathrm{G} \times \mathrm{E}$ effect was detected for SCS: Between herds with low and high BMSCC, the genetic variance increased 3fold and reranking of sires occurred. Early in lactation, heritabilities were greatest at high BMSCC, indicating more accurate testing of bulls under these circumstances. Responses to selection were reasonably high among environments in the second half of the lactation, whereas responses to selection between environments early and late in lactation tended to be low. Selection for reduced SCS yielded the highest direct response early in lactation at high BMSCC.

\section{ACKNOWLEDGMENTS}

This study was financially supported by the Ministry of Agriculture, Nature and Food Quality (Programme 414 "Maatschappelijk verantwoorde veehouderij"). The NRS (Dutch cattle improvement organization) is acknowledged for providing the data. The authors thank Johan van Arendonk, Piter Bijma, Jack Windig, and 2 anonymous reviewers for their suggestions and comments on the manuscripts.

\section{REFERENCES}

Banos, G., and G. E. Shook. 1990. Genotype by environment interaction and genetic correlations among parities for somatic-cell count and milk-yield. J. Dairy Sci. 73:2563-2573.

Barkema, H. W., Y. H. Schukken, T. Lam, M. L. Beiboer, G. Benedictus, and A. Brand. 1998a. Management practices associated with low, medium, and high somatic cell counts in bulk milk. J. Dairy Sci. 81:1917-1927.

Barkema, H. W., Y. H. Schukken, T. Lam, M. L. Beiboer, H. Wilmink, G. Benedictus, and A. Brand. 1998b. Incidence of clinical mastitis in dairy herds grouped in three categories by bulk milk somatic cell counts. J. Dairy Sci. 81:411-419.

Barkema, H. W., J. D. Van der Ploeg, Y. H. Schukken, T. J. G. M. Lam, G. Benedictus, and A. Brand. 1999. Management style and its association with bulk milk somatic cell count and incidence rate of clinical mastitis. J. Dairy Sci. 82:1655-1663.

Calus, M. P. L., L. L. G. Janss, J. J. Windig, B. Beerda, and R. F. Veerkamp. 2005a. Effectiveness of selection for lower somatic cell count (SCC) in herds with different levels of SCC. 56th Ann. Mtg. EAAP, June 5-8, Uppsala, Sweden.

Calus, M. P. L., J. J. Windig, and R. F. Veerkamp. 2005b. Associations between descriptors of herd management and phenotypic and genetic levels of health and fertility. J. Dairy Sci. 88:2178-2189.

Carlén, E., K. Jansson, and E. Strandberg. 2005. Genotype by environment interaction for udder health traits in Swedish Holstein cattle. 56th Ann. Mtg. EAAP, June 5-8, Uppsala, Sweden.

Castillo-Juarez, H., P. A. Oltenacu, R. W. Blake, C. E. McCulloch, and E. G. Cienfuegos-Rivas. 2000. Effect of herd environment on the genetic and phenotypic relationships among milk yield, conception rate, and somatic cell score in Holstein cattle. J. Dairy Sci. 83:807-814.

De Haas, Y., H. W. Barkema, Y. H. Schukken, and R. F. Veerkamp. 2003. Genetic associations for pathogen-specific clinical mastitis and patterns of peaks in somatic cell count. Anim. Sci. 77:187-195.

De Haas, Y., H. W. Barkema, and R. F. Veerkamp. 2002. The effect of pathogen-specific clinical mastitis on the lactation curve for somatic cell count. J. Dairy Sci. 85:1314-1323.

Dekkers, J. C. M., T. VanErp, and Y. H. Schukken. 1996. Economic benefits of reducing somatic cell count under the milk quality program of Ontario. J. Dairy Sci. 79:396-401.

Detilleux, J., and P. L. Leroy. 2000. Application of a mixed normal mixture model for the estimation of mastitis-related parameters. J. Dairy Sci. 83:2341-2349.

Emanuelson, U. 1988. Recording of production diseases in cattle and possibilities for genetic improvements-A review. Livest. Prod. Sci. 20:89-106.

Erskine, R. J., R. J. Eberhart, L. J. Hutchinson, S. B. Spencer, and M. A. Campbell. 1988. Incidence and types of clinical mastitis in dairy herds with high and low somatic-cell counts. J. Am. Vet. Med. Assoc. 192:761-765.

Falconer, D. S., and T. F. C. Mackay. 1996. Introduction to Quantitative Genetics. 4th ed. Longman Group, Essex, UK.

Gilmour, A. R., B. J. Gogel, B. R. Cullis, S. J. Welham, and R. Thompson. 2002. ASReml User Guide Release 1.0. VSN International, Hemel Hempstead, UK.

Haile-Mariam, M., M. E. Goddard, and P. J. Bowman. 2001. Estimates of genetic parameters for daily somatic cell count of Australian dairy cattle. J. Dairy Sci. 84:1255-1264.

Jaffrezic, F., E. Venot, D. Laloë, A. Vinet, and G. Renand. 2004. Use of structured antedependence models for the genetic analysis of growth curves. J. Anim. Sci. 82:3465-3473.

Kirkpatrick, M., D. Lofsvold, and M. Bulmer. 1990. Analysis of the inheritance, selection and evolution of growth trajectories. Genetics 124:979-993.

Koivula, M., E. Negussie, and E. A. Mantysaari. 2004. Genetic parameters for test-day somatic cell count at different lactation stages of Finnish dairy cattle. Livest. Prod. Sci. 90:145-157.

Mallard, B. A., J. C. Dekkers, M. J. Ireland, K. E. Leslie, S. Sharif, C. L. Vankampen, L. Wagter, and B. N. Wilkie. 1998. Alteration in immune responsiveness during the peripartum period and its ramification on dairy cow and calf health. J. Dairy Sci. 81:585595.

Miltenburg, J. D., D. deLange, A. P. P. Crauwels, J. H. Bongers, M. J. M. Tielen, Y. H. Schukken, and A. R. W. Elbers. 1996. Incidence of clinical mastitis in a random sample of dairy herds in the southern Netherlands. Vet. Rec. 139:204-207.

Nunez-Anton, V., and D. L. Zimmerman. 2000. Modeling nonstationary longitudinal data. Biometrics 56:699-705.

Odegard, J., J. Jensen, G. Klemetsdal, P. Madsen, and B. Heringstad. 2003. Genetic analysis of somatic cell score in Norwegian cattle using random regression test-day models. J. Dairy Sci. 86:4103-4114.

Philipsson, J., G. Ral, and B. Berglund. 1995. Somatic-cell count as a selection criterion for mastitis resistance in dairy-cattle. Livest. Prod. Sci. 41:195-200.

Pool, M. H., and T. H. E. Meuwissen. 2000. Reduction of the number of parameters needed for a polynomial random regression test day model. Livest. Prod. Sci. 64:133-145. 
Productschap Zuivel. 2004. Subject: Ontwerp-Verordening tot wijziging (1) van de Zuivelverordening 2003, Vaststelling frequentie en beoordeling resultaten kwaliteitsonderzoek. http://www. prodzuivel.nl/index.asp? frame $=\mathrm{http} \% 3 \mathrm{~A} / / \mathrm{www}$.prodzuivel.nl $/$ $\mathrm{pz} /$ productschap/bestuur/20030618/wijziging\%25201\%2520 vaststelling.htm Accessed May 4, 2004.

Raffrenato, E., R. W. Blake, P. A. Oltenacu, J. Carvalheira, and G. Licitra. 2003. Genotype by environment interaction for yield and somatic cell score with alternative environmental definitions. J. Dairy Sci. 86:2470-2479.

Samore, A. B., J. A. M. Van Arendonk, and A. F. Groen. 2001. Impact of area and sire by herd interaction on heritability estimates for somatic cell count in Italian Holstein Friesian cows. J. Dairy Sci. 84:2555-2559.
Schutz, M. M., P. M. Vanraden, and G. R. Wiggans. 1994. Genetic variation in lactation means of somatic cell scores for six breeds of dairy cattle. J. Dairy Sci. 77:284-293.

Veerkamp, R. F., A. W. Stott, W. G. Hill, and S. Brotherstone. 1998 The economic value of somatic cell count payment schemes for UK dairy cattle breeding programmes. Anim. Sci. 66:293-298.

Weller, J. I., A. Saran, and Y. Zeliger. 1992. Genetic and environmental relationships among somatic-cell count, bacterial-infection, and clinical mastitis. J. Dairy Sci. 75:2532-2540.

Wilson, D. J., H. H. Das, R. N. Gonzalez, and P. M. Sears. 1997. Association between management practices, dairy herd characteristics, and somatic cell count of bulk tank milk. J. Am. Vet. Med. Assoc. 210:1499-1502. 